\title{
Correction to: Comparison of two software systems for quantification of myocardial blood flow in patients with hypertrophic cardiomyopathy
}

\author{
Hulya Yalcin, MD, ${ }^{\mathrm{a}}$ Ines Valenta, $M D,{ }^{\mathrm{b}}$ Min Zhao, MD, ${ }^{\mathrm{b}, \mathrm{c}}$ Abdel Tahari, MD, ${ }^{\mathrm{b}}$ Dai- \\ Yin Lu, MD, , d,e Takahiro Higuchi, MD, ${ }^{\mathrm{f}}$ Fatih Yalcin, MD, ${ }^{\mathrm{a}}$ Nagehan Kucukler, \\ MD, ${ }^{a}$ Yalda Soleimanifard, MD, ${ }^{a}$ Yun Zhou, PhD, ${ }^{b}$ Martin G. Pomper, MD, PhD, ${ }^{b}$ \\ Theodore P. Abraham, MD, ${ }^{\mathrm{a}, \mathrm{g}}$ Ben Tsui, PhD, ${ }^{\mathrm{b}}$ Martin A. Lodge, PhD, ${ }^{\mathrm{b}}$ \\ Thomas H. Schindler, MD, ${ }^{b}$ and M. Roselle Abraham, $M^{a, g}$ \\ a Hypertrophic Cardiomyopathy Center of Excellence, Johns Hopkins School of Medicine, \\ Baltimore, MD \\ b Russell H. Morgan Department of Radiology and Radiological Science, Johns Hopkins School \\ of Medicine, Baltimore, MD \\ c Department of Nuclear Medicine, Xiangya Hospital, Central South University, Changsha, China \\ d Division of Cardiology, Department of Medicine, Taipei Veterans General Hospital, Taipei, \\ Taiwan \\ e Institute of Public Health, National Yang-Ming University, Taipei, Taiwan \\ f National Cerebral and Cardiovascular Center, Osaka, Japan \\ g Hypertrophic Cardiomyopathy Center, UCSF Division of Cardiology, San Francisco, CA
}

doi: $10.1007 / \mathrm{s} 12350-018-1228-5$

\section{CORRECTION TO: J NUCL CARDIOL \\ HTTPS://DOI.ORG/10.1007/S12350-017-1155-X}

The following information is missing from the Funding footnote on the first page of the published article: "This study was partly funded by NIH RO1 HL092985.',

The last/corresponding author is incorrectly listed on the first page of the published article: The correct name is Abraham MR.

\footnotetext{
The original article can be found online at https://doi.org/10.1007/ s12350-017-1155-x.

Reprint requests: M. Roselle Abraham, MD, Hypertrophic Cardiomyopathy Center, UCSF Division of Cardiology, 555 Mission Bay Blvd South, Smith Cardiovascular Research Building, 252G, San Francisco, CA 94158; Roselle.Abraham@ucsf.edu

J Nucl Cardiol 2019;26:1254.

$1071-3581 / \$ 34.00$

Copyright (c) 2018 American Society of Nuclear Cardiology. 